\title{
Inherited stress resistance and longevity: a stress theory of ageing
}

\author{
PETER A. PARSONS* \\ Department of Genetics and Human Variation, La Trobe University, Bundoora, Vic. 3083, Australia
}

\begin{abstract}
Ageing is considered in the context of the abiotic stresses to which free-living organisms are normally exposed. Assuming that the primary target of selection of stress is at the level of energy carriers, trade-offs under the rate-of-living theory of ageing predict increased longevity from selection for stress resistance. Changes in longevity then become incidental to selection for stress resistance. I therefore suggest the reformulation of the rate-of-living theory to become a stress theory of ageing. This directly incorporates the characteristics of habitats in nature. Under this theory, the primary trait inherited is resistance to stress. Consequently, at extreme ages those with inherited resistance to abiotic stress should dominate. Furthermore, the reduction in homeostasis manifested by deteriorating ability to adapt to abiotic stress as ageing proceeds, should be slowest in those surviving longest.
\end{abstract}

Keywords: abiotic stress, ageing, genetic variability, longevity, stress resistance, trade-off.

\section{Introduction}

Ageing is regarded as a complex process because the identification and characterization of underlying mechanisms tend to be elusive. Consequently, there are numerous and accumulating theories of ageing, of which evolutionary theories form one major category (Medvedev, 1990). There are, however, signs of convergence since Kowald \& Kirkwood (1994) recently argued for a Network Theory of Ageing, which underlies evolutionary theories based upon metabolic considerations emphasizing energy utilization. A common feature of evolutionary theories of ageing is that natural selection should favour youth over age, which has led to the antagonistic pleiotropy mechanism to explain ageing whereby early reproduction is correlated with early ageing and conversely, long-lived individuals exhibit a lower early reproductive rate (Williams, 1957; Rose, 1991). The object of this paper is to look at this approach in the context of the energetic costs of the environments of free-living populations.

In contrast, much experimental work on ageing, in particular in insects, has been based upon artificially benign laboratory environments. In the wild, lifespans are a small proportion of those obtainable in the laboratory. For example, Schnebel \& Grossfield (1988)

*Correspondence: Faculty of Science and Technology, Griffith University, Qld. 4111, Australia. record adult Drosophila melanogaster living beyond 100 days in the laboratory, which is inconceivable in nature. Similarly, for most of human recorded history, median life spans were in the 25 to 35 year range compared with values now exceeding 70 years in U.S. populations (Cutler, 1984). Therefore, to what extent are ageing studies in interpretative difficulties because of a concentration upon environments that are artificially benign following domestication? Indeed, there is evidence in captive animals that the capacity to tolerate temperature extremes falls after some generations indicating a relaxation of selection for stress resistance (Kohane \& Parsons, 1988).

Some Drosophila experiments on longevity illustrate the complications that can occur (Parsons, 1978). In $D$. simulans, soon after 20 laboratory-based isofemale strains were derived from natural populations, they were reared at $20^{\circ} \mathrm{C}$ and longevity measured at $20^{\circ} \mathrm{C}$ and $25^{\circ} \mathrm{C}$. At both temperatures, there was significant heterogeneity among strains indicating genetic polymorphism for longevity in natural populations, but there was a large and significant 'strain $\times$ temperature' interaction giving an almost total lack of correspondence of strain longevities across temperatures. The conclusion is that studies on the genetics of ageing are only relevant to the environment selected. In contrast, from an identically designed experiment in the sibling species, $D$. melanogaster, there was reasonable correspondence of longevities across temperatures. Arguing from interspecific competition experiments (Arthur, 
1987) and direct stress tests (Parsons, 1982), a possible ecological distinction between these species in that $25^{\circ} \mathrm{C}$ is somewhat more stressful for $D$. simulans than for $D$. melanogaster. This suggests that correspondences across environments could break down when differing stress levels are involved.

Ageing studies therefore need to be carried out bearing in mind the environments to which organisms are exposed. For some evolutionary biologists the occurrence of environmental perturbations of an unpredictable nature, typically involving climatic extremes, emphasizes the role of physical factors in the determination of the distribution and abundance of organisms. Accordingly, Hoffmann \& Parsons (1991) and Parsons (1993) summarized a diffuse literature on abiotic stress in free-living and fossil populations, and concluded that stress is important for many evolutionary and ecological processes. Even though biotic factors are often accorded a major role (Dunson \& Travis, 1991), they must normally be regarded as transient because of the environmental instability of most free-living populations.

In this paper, ageing will be considered bearing in mind the habitats of organisms, which as a first approximation can be reduced to an interaction between stress intensity, magnitude of (abiotic) environmental fluctuations and the energy available from resources. This model was recently used in considering evolutionary rates (Parsons, 1994), where the interaction of stress increasing energetic costs with energy provided from resources was central. Energetic trade-offs are pivotal in the discussion to follow. After a discussion of such trade-offs, genes affecting longevity and their phenotypic effects will be considered leading to a stress theory of ageing.

\section{Trade-offs and stress resistance}

In Drosophila, a negative correlation between longevity and specific metabolic rate occurs as a first approximation (Phillips \& Hilliker, 1990). For instance, using insects, increased temperature and metabolic rate tend to be associated with reduced lifespan (Miquel et al., 1976; Sohal, 1985). Conversely, a reduction of metabolic rate following the elimination of flying extended the lifespan (Sohal, 1985). These observations lead to the rate-of-living theory of ageing which postulates that the total metabolic expenditure of a genotype is relatively fixed. Consequently, the achieved longevity should depend on the rate at which this metabolic potential is depleted.

A frequent immediate response to abiotic stress is an increased metabolic rate (Hoffmann \& Parsons, 1991) and reduced longevity. In parallel, high metabolic rate
Table 1 Desiccation selection in Drosophila melanogaster

\begin{tabular}{|c|c|c|c|}
\hline & $\begin{array}{l}\text { Desiccation } \\
\left(\mathrm{LT}_{50} \text { hours }\right)\end{array}$ & $\begin{array}{c}\text { Metabolic rate } \\
\left(\mathrm{O}_{2} \mathrm{mg}(\text { wet weight })^{-1}\right. \\
\left.\mathrm{hr}^{-1}\right)\end{array}$ & $\begin{array}{l}\text { Longevity } \\
\text { in days }\end{array}$ \\
\hline Control & 15 & 3.2 & 84 \\
\hline Resistant & 24 & 2.7 & 106 \\
\hline
\end{tabular}

Simplified from Hoffmann \& Parsons (1989, 1993), where statistical analyses are provided.

mutants in $D$. melanogaster such as shaker tend to be stress-sensitive and short-lived (Barros et al., 1991; Parsons, 1993). Conversely, strains of D. melanogaster selected for increased longevity tend to show reduced metabolic rate and increased stress resistance (Rose, 1991 ), as well as increased antioxidant activity (Arking \& Wells, 1990).

There is much evidence for such trade-offs. In $D$. mercatorum, the allele for abnormal abdomen increases early fecundity but longevity is reduced (Templeton et al., 1985); underlying this polymorphism in nature are variable levels of desiccation stress. Hoffmann \& Parsons (1993) increased resistance to desiccation in $D$. melanogaster by selection; correlated responses include reduced metabolic rate and increased longevity (Table 1). In the hymenopterous parasite, Aphytis lingnanensis, longevity increased following selection for resistance to extreme temperature (White et al., 1970). These results are consistent with the rate-of-living theory and hence the antagonistic pleiotropy mechanism to explain ageing. Underlying these trade-offs are observed or implied reductions in metabolic rate in association with increases in stress resistance. This accounts for the difficulty in separating the effects of a range of stresses in D. melanogaster, including high temperature, desiccation, starvation, irradiation, and toxic levels of the resources ethanol and acetic acid (Hoffmann \& Parsons, 1989, 1991).

Under antagonistic pleiotropy, negative correlations are expected among early - and late - fitness traits; however, in a survey of published experiments, Schnebel \& Grossfield (1988) found a range from negative to positive correlations. Restricting the discussion to longevity selection data in $D$. melanogaster, negative correlations were found by Rose \& Charlesworth (1981) and fluctuating to positive correlations by Lints et al. (1979). In the former experiments the stress level was higher than in the latter, because competition between larvae occurred. Based upon data of Clare \& Luckinbill (1985), some stress from competition appears necessary to obtain a response to 
selection (Parsons, 1987), and hence the negative correlations expected under antagonistic pleiotropy.

\section{Inherited stress resistance}

Under extreme stress, especially when close to where population continuity is threatened, phenotypic and genotypic variability tends to be high. Ionizing radiation is a useful stress for ageing studies, because a major consequence of radiation is the production of free radicals causing oxidative damage to DNA, protein and lipid, so that oxidative stress is a major contributor to ageing (Ames et al., 1993). Furthermore, since the level of oxidative damage is roughly related to the basal metabolic rate among a range of mammalian species (Adelman et al., 1988), the rate-of-living theory can be reformulated as the free radical theory (Sohal, 1985, 1986; Arking, 1987). More generally, this reformulation can be incorporated into the Disposable Soma Theory of Ageing, which supports the idea that ageing is caused by the accumulation of random molecular defects in the cell (Kirkwood \& Holliday, 1979), so that an underlying molecular and physiological basis to ageing is emerging consistent with the recently proposed Network Theory of Ageing (Kowald \& Kirkwood, 1994).

Westerman \& Parsons (1973) studied the effects of ${ }^{60} \mathrm{Co} \gamma$-irradiation on longevity in $D$. melanogaster. The relative magnitude of the additive genetic component, as well as the relative importance of nonadditive and additive components, changed with the level of environmental stress (Table 2). In particular, under extreme stress where longevity was of the order of $1 / 10$ of unirradiated controls, the additive genetic component was high. Since as already noted, reduced metabolic rate is associated with resistance to a range

Table 2 Changes in relative importance of additive and nonadditive genetic effects for the longevity of Drosophila melanogaster measured at different levels of ${ }^{60} \mathrm{Co}$ $\gamma$-irradiation

\begin{tabular}{lrrrrrr}
\hline & \multicolumn{5}{c}{ Radiation dose (krad) } \\
\cline { 2 - 7 } & \multicolumn{1}{c}{0} & \multicolumn{1}{c}{40} & 60 & 80 & 100 & 120 \\
\hline Additive effects & 669.7 & 122.0 & 54.4 & 14.1 & 24.6 & 143.7 \\
Nonadditive effects & 380.5 & 221.9 & 83.6 & 52.0 & 43.7 & 19.6 \\
Error & 150.6 & 57.4 & 24.2 & 12.0 & 8.1 & 5.2 \\
\hline
\end{tabular}

Genetic effects were determined from an analysis of variance of the results of crosses between four inbred strains (numbers in the table are mean squares). The error term indicates environmental effects. (Modified from Westerman \& Parsons, 1973). of generalized stresses, including irradiation and desiccation, this translates into a high heritability, in parallel with ecologically important stresses such as desiccation. Under the stressful and energetically costly environment of natural populations, substantial additive genetic control of life history traits including longevity can therefore be inferred.

The process of ageing takes populations progressively towards the stressful boundary where extinction occurs. Therefore genetic variability should increase during ageing and should be highest at very late ages. For instance, in D. melanogaster Hughes \& Charlesworth (1994) found an increase in genetic (additive and dominance) and environmental variation among males at late ages, and Engström et al. (1992) found that additive genetic and environmental variation for the number of adult offspring increased with age in lines successfully selected for lifespan. In contrast, earlier data of Rose \& Charlesworth (1980) did not show an increase in additive genetic variance of fecundity with age; however, flies older than around 30 days old were not tested.

Arguing from the experimental data in Table 1, at extreme ages the survivors should be comparatively stress resistant when tested at matched age. In Caenorhabditis elegans, mutants with extended lifespan have increased starvation and oxidative stress resistance (Kenyon et al., 1993; Larsen, 1993). For oxidative stress, high superoxide dismutase (SOD) activity level in the mutant confers hyper-resistance to the superoxide-anion-generating drug paraquat (Vanfleteren, 1993). Similarly, in D. melanogaster paraquat resistance is correlated with longevity (Arking et al., 1991), and populations with postponed ageing and high resistance to irradiation had consistently high frequencies of an allele coding for high SOD activity (Tyler et al., 1993).

Certain individuals therefore can cope better with abiotic stress during the ageing process and this ability is under genetic control. In agreement, Vaupel (1988) considers that "what children inherit from their parents is not their longevity per se but rather their frailty that is, a set of susceptibilities and risk factors that alter their chances of death at different ages". This could explain experiments where a mortality rate reduction at older ages occurred in large cohorts of medflies, Ceratitis capita (Carey et al., 1992), because assuming that genetically frailer individuals die at earlier ages, those remaining should be the most robust and stress resistant. This is consistent with genetic heterogeneity of mortality patterns within populations which increases towards extreme ages.

The results so far considered were obtained under laboratory environments which is useful for standardi- 
zation. Under such conditions deleterious mutations should have the greatest chance of survival, because selection against them should be weaker than in freeliving populations. This could underlie laboratory data from D. melanogaster (Engström et al., 1992; Hughes \& Charlesworth, 1994) that appear to support the mutation-accumulation mechanism of ageing, whereby deleterious alleles accumulate at later ages (Rose, 1991). However, under strong selection from stress in natural populations, these mutants should not survive for long, so that senescence by this mechanism could be an artifact of benign environments. In agreement, there are many examples of mutants that do not inactivate enzymes and are heat sensitive (Langridge, 1968; Homyk et al., 1980); these would be vulnerable in stressful environments. Therefore in conclusion, deleterious mutants may reinforce the ageing process in natural populations.

There is a need to characterize long-lived individuals physiologically and genetically emphasizing resistance to environmental extremes. In this connection, the maximum potential lifespan in human populations from classical Greek and Roman times to this day appears to be around 95 years, but during this period the median age for 50 per cent survival has at least doubled (Cutler, 1984). This situation implies strong selection from stress throughout most of human existence, but the concomitant of increased longevity from stress-based selection (Table 1) would not be expressed except for a few outlier individuals. Today, selection for stress resistance is less intense than in earlier times so that extending the maximum lifespan may be difficult assuming an association between stress resistance and longevity. In fact, there is an overall loss in the potential of the old to adapt to thermal stress, because body temperature oscillates between wider limits of internal temperature compared with younger ages (Crews, 1993). In parallel, tumours increase in frequency with age and are more heat sensitive than surrounding tissues (Overgaard, 1989). Ageing therefore can be regarded as a process of progressively falling homeostasis in response to the stresses of the habitats in which organisms live. Interestingly, one of the loci studied by Schächter et al. (1994) for their impact on human longevity in centenarians is important in the control of blood pressure, salt and water homeostasis, and the control of cell growth. This suggests a genetic component in generalized homeostasis associated with stress resistance.

\section{Discussion}

Genetical studies in D. melanogaster indicate that chromosome 3 underlies a substantial portion of observed response to selection for longevity (Luckinbill et al., 1988; Buck et al., 1993). There is a need for parallel substitution line experiments on a direct stress trait such as desiccation, where extremely high heritabilities (in excess of 0.6) have been recorded (Hoffmann \& Parsons, 1991). In contrast, estimated heritabilities of lifespan in Drosophila are lower - in the range of 0.11-0.44 (Yonemura et al., 1989). Both lifespan and resistance to stress should be assayed in selection experiments whatever the trait under direct selection. Considering stress, from data covering a wide range of animal and plant taxa, Riddoch (1993) finds that the more anodal allozyme/isozyme at the phosphoglucose isomerase, $P G I$, locus is favoured under stressful conditions including high temperature, high salinity, anoxia and desiccation. This suggests at least one locus in natural populations of importance in determining resistance to stress. This situation is not surprising since in vitro biochemical studies of PGI allozymes suggest that this enzyme is a direct target of selection of stress (Watt, 1983; Riddoch, 1993).

Assuming the target of selection of stress is at the level of energy carriers, the trade-offs expected under the rate-of-living theory of ageing predict that selection for stress resistance should directly increase longevity. This reformulates the rate-of-living theory to become a stress theory of ageing. Extrapolating to closely related species, those that are stress resistant should have the longest lifespan. For example, in subgenus Sophophora of genus Drosophila, Schnebel \& Grossfield (1988) rank longevities of $D$. melanogaster $>D$. ananassae $>$ $D$. paulistorum, which corresponds to a ranking of resistances to desiccation stress (Parsons, 1982). Based upon the assumed importance of abiotic stresses in natural populations, the variations in longevity should be incidental to selection for stress resistance.

In rodents, dietary restriction compared with unlimited food can increase longevity. This implies that excess food can be stressful. Excess food leads to elevated metabolic rate and elevated free radical production, and conversely dietary restriction leads to an antiageing effect at the cellular level (Pieri et al., 1992). Unlimited metabolic capacity should be selected against because of its metabolic cost. This follows from indications that animals evolve the metabolic capacity appropriate to their habitats in nature (Diamond \& Hammond, 1992). These deductions are compatible with a target of selection at the level of energy carriers.

Koehn \& Bayne (1989) argue that high stress resistance is associated with the efficient use of metabolic resources, so that individuals with a high level of efficiency can maintain growth and reproduction over a wide range of environmental conditions especially 
when resources are limited. In other words, a genotype with a low maintenance requirement can support growth over a wide range of environmental conditions. Furthermore, such individuals should show substantial homeostasis in response to stressful environments and should live longest. Since fluctuating morphological asymmetry, FA, is a measure of homeostasis (Thoday, 1958) in various environments (Parsons, 1992), the least asymmetric individuals therefore should live longest. This was demonstrated in the forest tent caterpillar moth, Malacosoma disstria, where FA of the first tarsal segment of the proleg was significantly inversely related to survival ability under laboratory conditions (Naugler \& Leech, 1994). Therefore, individuals that have inherited high stress resistance and live longest should be the most symmetrical at a given age.

\section{Acknowledgements}

I am most grateful to Ary Hoffmann whose suggestions improved this manuscript greatly, and to J. H. Bennett for detailed comments.

\section{References}

ADELMAN, R., SAUL, R. L. AND AMES, B. N. 1988. Oxidation damage to DNA: relation to species metabolic rate and life span. Proc. Natl. Acad. Sci. U.S.A., 85, 2706-2708.

AMES, B. N., SHIGENAGA, M. K. AND haGEN, T. M. 1993. Oxidants, antioxidants, and the degenerative diseases of aging. Proc. Natl. Acad. Sci. U.S.A., 90, 7915-7922.

ARKING, R. 1987. Genetic and environmental determinants of longevity in Drosophila. In: Woodhead, A. D. and Thompson, K. H. (eds) Evolution of Longevity in Animals, pp. 1-22. Plenum Press, New York.

ARKING, R., BUCK, S., BERRIOS, A., DWYER, S. AND BAKER, G. T., III. 1991. Elevated paraquat resistance can be used as a bioassay for longevity in a genetically based long-lived strain of Drosophila. Devl. Genet., 12, 362-370.

ARKING, R. AND WELLS, R. A. 1990. Genetic alteration of normal aging processes is responsible for extended longevity in Drosophila. Devl. Genet., 11, 141-148.

ARTHUR, w. 1987. The Niche in Competition and Evolution. John Wiley, New York.

BARROS, A. R., SIERRA, L. M. AND COMENDADOR, M. A. 1991. Decreased metabolic rate as an acrolein resistance mechanism in Drosophila melanogaster. Behav. Genet., 21, 445-451.

BUCK, S., WELLS, R. A., DUDAS, S. P., BAKER, G. T., III AND ARKING, R. 1993. Chromosomal localization and regulation of the longevity determinant genes in a selected strain of Drosophila melanogaster. Heredity, 71, 11-22.

CAREY, J. R., LIEDO, P., OROZCO, D. AND VAUPEL, J. w. 1992. Slowing of mortality rates at older ages in large medfly cohorts. Science, 258, 457-460.
ClARE, M. J. AND LUCKINBILL, L. S. 1985. The effects of gene-environment interaction on the expression of longevity. Heredity, 55, 19-29.

CREWS, D. E. 1993. Biological anthropology and human aging: some current directions in aging research. Ann. Rev. Anthrop., 22, 395-423.

CUTLER, R. G. 1984. Antioxidants, aging, and longevity. In: Pryor, W. A. (ed.) Free Radicals in Biology, Vol. V, pp. 371-428. Academic Press, Orlando, FL.

DIAMOND, J. M. AND HAMMOND, K. A. 1992. Intestinal determinants of muscle performance. Adv. BioSci., 84, 163-170.

DUNSON, W. A. AND TRAVIS, J. 1991. The role of abiotic factors in community organization. Am. Nat., 138, 1068-1091.

ENGSTROM, G., LILJEDAHL, L.-E. AND BJÖRKLUND, T. 1992. Expression of genetic and environmental variation during ageing 2. Selection for increased lifespan in Drosophila melanogaster. Theor. Appl. Genet., 85, 26-32.

HOFFMANN, A. A. AND PARSONS, P. A. 1989. Selection for increased desiccation resistance in Drosophila melanogaster: additive genetic control and correlated responses for other stresses. Genetics, 122, 837-845.

HOFFMANN, A. A. AND PARSONS, P. A. 1991. Evolutionary Genetics and Environmental Stress. Oxford University Press, Oxford.

HOFFmanN, A. A. AND PARSONS, P. A. 1993. Selection for adult desiccation resistance in Drosophila melanogaster: fitness components, larval resistance and stress correlations. Biol. J. Linn. Soc., 48, 43-54.

HOMYK, T., SZIDONYA, J. AND suzuki, D. T. 1980. Behavioral mutants of Drosophila melanogaster. III. Isolation and mapping of mutations by direct visual observations of behavioral phenotypes. Mol. Gen. Genet., 177, 553-565.

HUGHES, K. A. AND CHARLESWORTH, B. 1994. A genetic analysis of senescence in Drosophila. Nature, 367, 64-66.

KENYON, C., CHANG, J., GENSCH, E., RUDNER, A. AND TABTIANO, R. 1993. A $C$. elegans mutant that lives twice as long as wild type. Nature, 366, 461-464.

KIRKWOOD, T. B. L. AND HOLLIDAY, R. 1979. The evolution of ageing and longevity. Proc. R. Soc. B, 205, 531-546.

KOEHN, R. K. AND BAYNE, B. L. 1989. Towards a physiological and genetical understanding of the energetics of the stress response. Biol. J. Linn. Soc., 37, 157-171.

KOHANE, M. J. AND PARSONS, P. A. 1988. Domestication: evolutionary change under stress. Evol. Biol., 23, 31-48.

KOWALD, A. AND KIRKWOOD, T. B. L. 1994. Towards a network theory of ageing: a model combining the free radical theory and the protein error theory. J. Theor. Biol., 168, 75-94.

LANGRIDGE, J. 1968. Thermal responses of mutant enzymes and temperature limits to growth. Mol. Gen. Genet., 103, 116-126.

LARSEN, P. L. 1993. Aging and resistance to oxidative damage in Caenorhabditis elegans. Proc. Natl. Acad. Sci. U.S.A., 90, 8905-8909.

LiNTS, F. A., STOLL, J., GRUWEZ, G. AND LiNTS, c. v. 1979. An attempt to select for increased longevity in Drosophila melanogaster. Gerontology, 25, 192-204. 
LUCKINBILL, L. S., GRAVES, J. L., REED, A. H. AND KOETSAWANG, S. 1988. Localizing genes that defer senescence in Drosophila melanogaster. Heredity, 60, 367-374.

MEDVEDEV, Z. A. 1990. An attempt at a rational classification of theories of ageing. Biol. Rev., 65, 375-398.

MIQUEL, J., LUNDGREN, P. R., BENSCH, K. G. AND ATLAN, H. 1976. Effects of temperature on the life span, vitality and fine structure of Drosophila melanogaster. Mech. Ageing Devel., 5, 347-370.

NAUGLER, C. T. AND LEECH, S. M. 1994. Fluctuating asymmetry and survival ability in the forest tent caterpillar moth Malacosoma disstria: implications for pest management. Entomologia exp. appl., 70, 295-298.

OVERGAARD, J. 1989. The current and potential role of hyperthermia in radiotherapy. Int. J. Radiat. Oncol. Biol. Phys., 16, 535-549.

PARSONS, P. A. 1978. The genetics of aging in optimal and stressful environments. Exp. Geront., 13, 357-363.

PARSONS, P. A. 1982. Evolutionary ecology of Australian Drosophila: a species analysis. Evol. Biol., 14, 297-350.

PARSONS, P. A. 1987. Evolutionary rates under environmental stress. Evol. Biol., 21, 311-347.

PARSONS, P. A. 1992. Fluctuating asymmetry: a biological monitor of environmental and genomic stress. Heredity, 68, 361-364.

PARSONS, P. A. 1993. The importance and consequences of stress in living and fossil populations: from life-history variation to evolutionary change. Am. Nat., 142, S5-S20.

PARSONS, P. A. 1994. Habitats, stress, and evolutionary rates. J. Evol. Biol., 7, 387-397.

PHILlJPS, J. P. AND HILlikeR, A. J. 1990. Genetic analysis of oxygen defense mechanisms in Drosophila melanogaster. Adv. Genet., 28, 43-71.

PIERI, C., FALASCA, M., RECCHIONI, R., MORONI, F. AND MARCHESELLI, F. 1992. Diet restriction: a tool to prolong lifespan of experimental animals. Models and current hypotheses of action. Comp. Biochem. Physiol., 103A, 551-554.

RIDDOCH, B. J, 1993. The adaptive significance of electrophoretic mobility in phosphoglucose isomerase (PGI). Biol. J. Linn. Soc., 50, 1-17.

ROSE, M. R. 1991. Evolutionary Biology of Aging. Oxford University Press, New York.

ROSE, M. R. AND CHARLESWORTH, B. 1980. A test of evolutionary theories of senescence. Nature, 287, 141-142.

ROSE, M. R. AND CHARLESWORTH, B. 1981. Genetics of life history in Drosophila melanogaster. II. Exploratory selection experiments. Genetics, 97, 187-196.
SCHÄCHTER, F., FAURE-DELANEF, L., GUENOT, F., ROUGER, H., FROGUEL, P., LESUEUR-GINOT, L. AND COHEN, D. 1994. Genetic associations with human longevity at the $A P O E$ and $A C E$ loci. Nature Genetics, 6, 29-32.

SCHNEBEL, E. M. AND GROSSFIELD, J. 1988. Antagonistic pleiotropy: an interspecific Drosophila comparison. Evolution, 42, 306-311.

SOHAL, R. S. 1985. Aging in insects. In: Kerkut, G. A. and Gilbert, L. I. (eds) Comprehensive Insect Physiology, Biochemistry and Pharmacology, vol. 10, pp. 595-631. Pergamon Press, Oxford.

SOHAL, R. S. 1986. The rate of living theory: a contemporary interpretation. In: Collatz, K. G. and Sohal, R. S. (eds) Insect Aging, pp. 23-44. Springer-Verlag, Berlin.

TEMPLETON, A. R., CREASE, T. J. AND SHAH, F. 1985. The molecular through ecological genetics of abnormal abdomen in Drosophila mercatorum. I. Basic genetics. Genetics, 111, 805-818.

THODAY, J. M. 1958. Homeostasis in a selection experiment. Heredity, 12, 401-415.

TYLER, R. H., BRAR, H., SINGH, M., LATORRE, A., GRAVES, J. L., MUELLER, L. D., ROSE, M. R. AND AYALA, F. J. 1993. The effect of superoxide dismutase alleles on aging in Drosophila. Genetica, 91, 143-149.

VANFLETEREN, J. 1993. Oxidative stress and aging in Caenorhabditis elegans. Biochem. J., 292, 605-608.

VAUPEL, J. W. 1988. Inherited frailty and longevity. Demography, 25, 277-287.

WATT, w. B. 1983. Adaptation at specific loci. II. Demographic and biochemical elements in the maintenance of the Colias PGI polymorphism. Genetics, 103, 691-724.

WESTERMAN, J. M. AND PARSONS, P. A. 1973. Variation in genetic architecture at different doses of $\gamma$-radiation as measured by longevity in Drosophila melanogaster. Can. J. Genet. Cytol., 15, 289-298.

WHITE, E. B., DEBACH, P. AND GARBER, M. J. 1970. Artificial selection for genetic adaptation to temperature extremes in Aphytis lingnanensis (Hymenoptera: Aphelinidae). Hilgardia, 40, 161-192.

Williams, G. c. 1957. Pleiotropy, natural selection, and the evolution of senescence. Evolution, 11, 398-411.

YONEMURA, I., MOTOYAMA, T. AND HASEKURA, H. 1989. Mode of inheritance of major genes controlling life span differences between two inbred strains of Drosophila melanogaster. Hereditas, 111, 207-214. 